\title{
Uma Proposta de Protocolo MAC com Redução de Sobrecarga para Redes de Sensores sem Fio
}

\author{
Gunnar Ramos Fermino \\ Faculdade de Ciências Exatas e Tecnológica (FACET) \\ Universidade do Estado de Mato Grosso (UNEMAT) \\ Cáceres-MT, Brasil, 78217-900 \\ gunnar.ramos@unemat.br
}

\author{
Renato Mariz de Moraes \\ Centro de Informática (CIn) \\ Universidade Federal de Pernambuco (UFPE) \\ Recife-PE, Brasil, 50740-560 \\ renatomdm@cin.ufpe.br
}

\begin{abstract}
Resumo-Em redes de sensores sem fio (RSSFs) a eficiência energética é o principal problema de pesquisa. Tendo em vista a limitada reserva de energia dos nós sensores e o alto custo energético para transmitir e receber dados, definir a quantidade de dados de controle necessários à manutenção da RSSF é um grande problema. Este trabalho apresenta o MAC-RSPC, uma proposta de protocolo MAC para Redução de Sobrecarga de Pacotes de Controle, destinado a RSSFs multicanais e homogêneas. O MAC-RSPC segue a abordagem cross-layer e visa a eficiência energética. A técnica de redução de sobrecarga visa diminuir a quantidade de dados de controle que circulam na rede sem, no entanto, diminuir a qualidade dos dados disponíveis para manutenção da estrutura da rede e construção de rotas.

Index Terms-Eficiência energética, protocolo MAC, Redes de sensores sem fio, RSSF.
\end{abstract}

Abstract-In wireless sensor networks (WSNs), energy efficiency is the main research issue. Because of the limited power reserve of the sensor nodes and the high energy cost to transmit and receive data, define the number of control data necessary to maintain the WSN is a critical issue. This paper presents the MAC-RSPC, a proposed MAC protocol for Reducing Control Pack Overhead, intended for multichannel and homogeneous WSNs. MAC-RSPC follows the cross-layer approach and aims at energy efficiency. The overhead reduction technique aims to decrease the amount of control data that circulates on the network without, however, reduce the quality of the data available for maintaining the network structure and building routes.

Index Terms-Energy efficiency, MAC protocol, wireless sensor networks, WSN.

\section{INTRODUÇÃo}

As redes de sensores sem fio (RSSFs) são formadas por grupos de dezenas ou até milhares de nós sensores que possuem pouca memória, baixa capacidade de processamento, baixa potência de transmissão e são alimentados por pequenas baterias. Essas redes têm diversas finalidades e podem ser utilizadas em inúmeras aplicações civis e militares [1], [2].

A eficiência energética é a maior questão de pesquisa em RSSFs, pois a reposição de baterias em nós sensores, em muitos cenários, além de inviável pode ser impossível [2]. Nesse contexto, o rádio transmissor é o principal consumidor de energia em um nó sensor devido ao envio e recepção de dados e o processo de escuta ociosa (idle listening) [3].

Este trabalho foi financiado em parte pela Universidade do Estado de Mato Grosso (UNEMAT) e pelo Centro de Informática (CIn) da Universidade Federal de Pernambuco (UFPE).
Segundo [4] o custo energético para se transmitir 1 bit pode ser igual ao de executar o processamento de alguns milhares de instruções.

A construção, manutenção e o conhecimento da estrutura de uma rede de sensores sem fio pode exigir o envio de grandes quantidades de pacotes de controle e aumentar o desperdício de energia. Neste sentido, este trabalho propõe um protocolo de acesso ao meio (MAC, do inglês medium access control) energeticamente eficiente, cross-layer, para RSSFs multicanais e homogêneas. Este adota uma abordagem híbrida para controlar o acesso ao meio sem fio. É proposto, ainda, uma técnica para reduzir a sobrecarga de pacotes de controles (RSPC) enviados na rede, sem no entanto, diminuir a qualidade e a quantidade dos dados de controle disponíveis em cada nó. Nomeamos essa abordagem de protocolo MAC para Redução de Sobrecarga de Pacotes de Controle (MACRSPC) em RSSFs.

É realizada, também, uma demonstração do potencial de redução de sobrecarga (overhead) de dados de controle da RSPC. Com essa técnica é possível que os nós da rede disponham de uma grande quantidade de informações dos vizinhos a até dois saltos e com reduzido overhead. Isso permite que decisões de roteamento possam levar em conta a qualidade do sinal, o balanceamento do consumo energético e a tolerância à falhas das possíveis rotas.

O restante deste trabalho está organizado da seguinte forma. Na Seção II são apresentados os trabalhos relacionados. Na Seção III é feita a especificação da proposta do protocolo MAC-RSPC. Na Seção IV é descrita a técnica de redução de overhead aqui proposta e na Seção V é feita a demonstração do seu potencial de redução de overhead. Por fim, na Seção VI são apresentadas a conclusões sobre o trabalho.

\section{TRABALhos RELACIONADOS}

Em redes sem fio, protocolos MAC têm por finalidade gerenciar o acesso compartilhado ao canal de rádio evitando que colisões de pacotes aconteçam [5]. Em RSSFs, esses protocolos têm de garantir a transferência confiável de dados, gerenciar a interferência na rede e lidar com a economia de energia na intenção de aumentar o tempo de vida dos nós e da rede. Assim, nessas redes, métricas de desempenho de consumo de energia e tempo de vida são primárias enquanto 
que outras como vazão de dados, latência e segurança são em geral consideradas como secundárias [1].

A maioria dos protocolos MAC, cientes do consumo energético, limitam o tempo que o rádio do nó fica ligado em relação ao tempo que fica inativo (dormindo) ou desligado, abordagem conhecida como duty cycle reduzido. Protocolos MAC que fazem uso dessa abordagem são classificados como síncronos ou assíncronos [6].

Protocolos MAC síncronos criam uma agenda para que o par de nós, transmissor e receptor, durmam e acordem ao mesmo tempo a fim de economizarem energia. Essa abordagem emprega acesso ao meio por divisão do tempo (TDMA, do inglês Time Division Multiple Access). Ou seja, nessa abordagem toda comunicação é agendada de forma que não há disputa para aceso ao canal. Entretanto, em cenários com múltiplos saltos, a sincronização do tempo pode demandar alta sobrecarga de pacotes de controle na rede [3].

Já em protocolos MAC assíncronos um nó acessa o meio após sentir a portadora por um determinado período até constatar que o canal está livre. Essa abordagem é conhecida como CSMA (Carrier Sense Multiple Access) e é baseada na contenção entre os nós. Ela é eficiente energeticamente em redes com baixa taxa de tráfego, todavia, apresenta alto consumo de energia, colisões e disputas quando o tráfego é alto [3], [7].

Para melhorar o desempenho das RSSFs e reduzir o consumo energético, projetos cross-layer têm sido propostos [8]. Essa técnica consiste no projeto de protocolos para redes de computadores que violam o modelo de arquitetura em camadas a fim de obter ganhos em performance, por explorar as dependências e interações entre protocolos de camadas diferentes [8], [9].

Para avaliar a qualidade do sinal de um enlace e estimar a distância entre o transmissor e o receptor, muitos trabalhos têm usado o indicador de intensidade do sinal recebido (RSSI, do inglês Received Signal Strength Indicator) [10], [11]. Embora a distância estimada com base no RSSI não seja precisa é possível reduzir o erro no posicionamento utilizando técnicas como a apresentada em [10].

Diversos protocolos MAC, energeticamente eficientes, para RSSFs têm sido propostos nos últimos anos. No trabalho de [12] é apresentado o algoritmo CEE (do inglês, Connectivity and Energy Efficiency). O CEE atua com base na energia residual na distância relativa dos nós e acorda apenas os nós extremamente necessários para garantir a conectividade da rede a fim de reduzir o consumo energético e aumentar o tempo de vida da rede. Em [13] é proposto o TREEM, protocolo MAC que visa melhorar a transmissão de dados e a eficiência energética em redes de sensores tolerantes a atrasos (DTSN). Em [14] é apresentado o protocolo NSMAC o qual controla dinamicamente o tamanho do duty cycle com base na carga de trabalho da rede e, com isso, reduz o consumo energético. Em [4] é apresentado o AH-MAC, que é uma otimização, cross-layer, que combina o protocolo de roteamento LEACH e o protocolo MAC do padrão IEEE 802.15.4. No trabalho [15] é apresentado o ADP-MAC que é um protocolo MAC que salta entre canais de maneira dinâmica e adaptativa com base na variação do tráfego em cada canal a fim de reduzir o consumo energético. No trabalho de [16] é proposto o ADMC-MAC, um protocolo MAC assíncrono, energeticamente eficiente destinado a RSSFs com aplicações de missão críticas e se baseia nas condições de tráfego e no comprimento da fila de pacotes.

No melhor do nosso conhecimento, não foi encontrado um trabalho que proponha um protocolo MAC cross-layer, para RSSFs multicanal e homogênea, que faça controle de acesso ao meio de maneira híbrida como proposto neste trabalho. $\mathrm{E}$ que, também utilizem uma técnica de redução de sobrecarga de dados de controle (RSPC) na rede, de forma a permitir o compartilhamento de dados sobre a energia residual, o RSSI e o grau de conectividade de cada nó e de seus vizinhos.

\section{ESPECIFICAÇÃO DA PROPOSTA DO PROTOCOLO MAC}

Para a proposta do protocolo MAC-RSPC, assume-se uma RSSF com nós de configurações homogêneas e uma estação base (BS, do inglês Base Station) com múltiplas antenas e abundante reserva de energia. Os nós podem se movimentar em baixa velocidade, como em uma caminhada. Os nós podem entrar e sair da rede a qualquer momento seja pela mobilidade ou por terem esgotado suas reservas de energia. Assume-se, ainda, que o sinal de rádio da BS pode alcançar todos os nós da rede.

O modelo de RSSF aqui proposta é estruturada em níveis contados a partir da BS, conforme Fig. 1. Nesse trabalho, nível representa a distância do nó, em número de saltos, em relação à $\mathrm{BS}$ e é representado pela letra $h$. Como se observa na Fig. 1 o nível da BS é sempre zero $(h=0)$. No exemplo, se o nó transmissor (Tx), pintado de cinza, está localizado no nível $h$, logo seus vizinhos $3,4,5$ pertencem ao nível $h-1$ e assim sucessivamente.

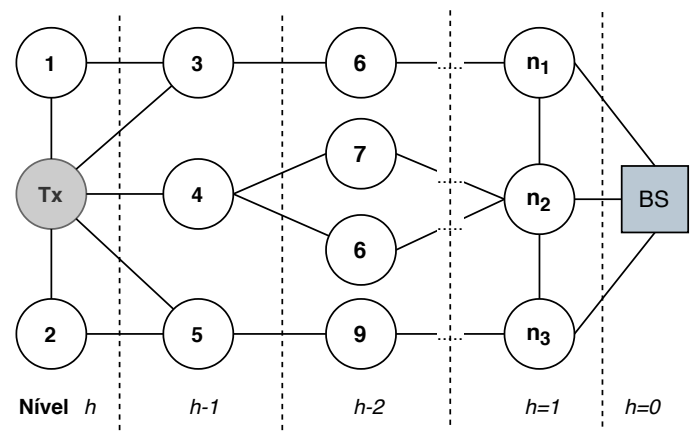

Figura 1. RSSF estruturada em níveis em relação à estação base (BS).

O protocolo MAC-RSPC faz acesso ao meio de maneira híbrida, usando as abordagens de acesso múltiplo com detecção de portadora e prevenção de colisão (CSMA/CA) e acesso múltiplo por divisão de tempo (TDMA). O tempo é dividido em superquadros os quais, por sua vez, são divididos em períodos ativo e inativo. O período ativo é composto por período de contenção para acesso ao meio (PCA) e pelo período livre de contenção para acesso ao meio (PLC). O 
superquadro é delimitado por pacotes de sinalização, aqui denominados de BF (do inglês Beacon Frames). O intervalo de tempo reservado para o envio do $\mathrm{BF}$ é representado pelos retângulos pretos no início e no final da Fig. 2.

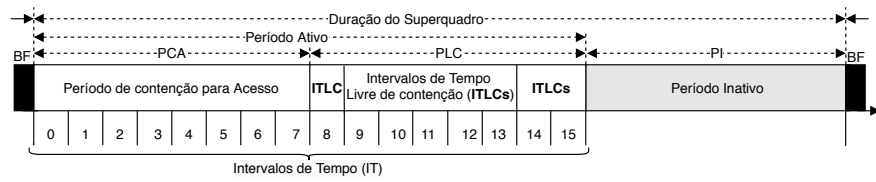

Figura 2. Superquadro de tempo da proposta de protocolo MAC-RSPC.

Quando a BS envia um pacote BF, todos os nós já devem estar acordados para receberem essa mensagem e para sincronizarem seus relógios com a BS. A BS emprega máxima potência de transmissão para que o $\mathrm{BF}$ alcance todos os nós da rede. $\mathrm{O}$ BF é utilizado para sincronizar os relógios dos nós e evitar o problema da variação de relógios (clock drift) [17]. Na Fig. 3 é apresentada a estrutura desse pacote BF que traz dados sobre a duração do superquadro e dos períodos PCA e PLC.

\begin{tabular}{|c|c|c|c|c|}
\hline Bytes: $\mathbf{4}$ & $\mathbf{4}$ & $\mathbf{2}$ & $\mathbf{2}$ & $\mathbf{2}$ \\
\hline úmero sequência & Hora atual & Comprimento superquadro & Comprimento PCA & Comprimento PLC \\
\hline
\end{tabular}

Figura 3. Estrutura do quadro de sinalização (BF).

Depois do BF, se inicia o período PCA onde cada nó permanece acordado para receber e transmitir pacotes de controle (PC). Os PCs são enviados por difusão e o acesso ao meio, para enviá-los, ocorre após disputa entre os nós, utilizando a abordagem CSMA/CA, conforme proposto no padrão IEEE 802.15.4 (Slotted CSMA/CA) [5].

Durante o PLC, utilizando a abordagem TDMA, os pares de nós, origens e destinos, transmitem seus dados nos canais e nos intervalos de tempo combinados durante o PCA. Já os demais nós, que não participam de nenhuma transmissão, desligam seus rádios até o próximo superquadro.

No período inativo (PI), todos os nós desligam seus rádios transmissores a fim de economizarem energia. A exceção é quando emissor e receptor necessitam de mais tempo, além do comprimento do PLC, para concluírem sua transmissão.

$\mathrm{O}$ período ativo do superquadro é divido, ainda, em 16 intervalos de tempo (ITs) de igual comprimento (parte inferior da Fig. 2). Os 16 ITs são divididos em partes iguais entre o PCA e o PLC. Durante o PLC cada IT é denominado intervalo de tempo livre de contenção (ITLC). O par, origem e destino, que agenda uma transmissão para o PLC, pode reservar um ou mais ITLCs para o envio de dados. Caso os ITLCs, disponíveis no PLC, não sejam suficientes para completar a transmissão, mais ITs podem ser criados e reservados durante o período inativo (PI).

Para o compartilhamento de informações na rede, três tipos de mensagens (pacotes) são propostas. O primeiro é o pacote de sinalização (BF) enviado pela BS (Fig. 3). O segundo é o pacote de controle (PC) enviado pela $\mathrm{BS}$ e pelos demais nós, durante o PCA. O terceiro, é o pacote de confirmação de que o meio está livre para transmitir (CTS, do inglês clear to send) que é enviado pelo nó destino de um PC que carrega uma RTS (do inglês request to send).

\section{A. Estrutura do Pacote de Controle (PC)}

$\mathrm{O}$ pacote $\mathrm{PC}$ é a principal mensagem de controle do MAC-RSPC. Cada nó sensor envia um único pacote PC por superquadro e, somente, depois de ter recebido um PC da BS ou de um nó vizinho.

$\mathrm{O}$ pacote $\mathrm{PC}$ tem várias finalidades, tais como: permitir o conhecimento dos vizinhos a até 2 saltos para a manutenção da estrutura da rede; fornecer dados que auxiliam o protocolo de roteamento na escolha do próximo salto, em direção à BS; difundir a agenda TDMA de cada nó, a fim de permitir transmissão simultânea em canais e ITLCs diferentes; e permitir que os pares, transmissor e receptor, combinem o canal e os ITLCs que serão utilizados para a troca de dados durante o PLC.

A estrutura do pacote PC é apresentada na Fig. 4. A parte branca da figura representa um PC padrão o qual possui os seguintes campos: Dados Controle; ID do transmissor; número de saltos, que representa o nível do transmissor do $\mathrm{PC}$ em relação à $\mathrm{BS}$; e Tempo restante, que carrega o tempo que falta para terminar o superquadro. Já a parte cinza contém os campos extras que podem ou não estar presentes no PC, os quais são descritos nas próximas seções.

\begin{tabular}{|c|c|c|c|c|c|c|c|}
\hline Bytes: $\mathbf{1}$ & $\mathbf{4}$ & $\mathbf{2}$ & $\mathbf{4}$ & Variável & Variável & Variável & Variável \\
\hline $\begin{array}{c}\text { Dados } \\
\text { Controle }\end{array}$ & $\begin{array}{c}\text { ID } \\
\text { Transmissor }\end{array}$ & N. Saltos & $\begin{array}{c}\text { Tempo } \\
\text { restante }\end{array}$ & $\begin{array}{c}\text { Dados extras } \\
\text { transmissor }\end{array}$ & $\begin{array}{c}\text { Dados } \\
\text { vizinhos }\end{array}$ & RTS & $\begin{array}{c}\text { Agenda } \\
\text { TDMA }\end{array}$ \\
\hline
\end{tabular}

Figura 4. Pacote de Controle (PC) com possíveis campos extras.

1) Estrutura do Campo "Dados Controle"do Pacote PC: O campo Dados Controle especifica o superquadro e o conteúdo do PC. Este possui 1 byte de comprimento e cada bit representa um dos dados extras que podem ser acrescentados no PC a ser enviado (Fig. 5), conforme descritos a seguir.

\begin{tabular}{|l|l|l|l|l|c|c|}
\hline Bit: $\mathbf{0}$ & \multicolumn{1}{|c|}{$\mathbf{1}$} & $\mathbf{2}$ & \multicolumn{1}{|c|}{$\mathbf{3}$} & $\mathbf{4}$ & $\mathbf{5}$ & $\mathbf{6 - 7}$ \\
\hline $\begin{array}{l}\text { PC } \\
\text { Comum }\end{array}$ & $\begin{array}{l}\text { Dados } \\
\text { transmissor }\end{array}$ & $\begin{array}{l}\text { Dados } \\
\text { vizinhos }\end{array}$ & $\begin{array}{l}\text { Dados vizinhos } \\
\text { completo }\end{array}$ & $\begin{array}{l}\text { Dados vizinhos } \\
\text { parcial }\end{array}$ & $\begin{array}{l}\text { Tem } \\
\text { RTS? }\end{array}$ & Uso futuro \\
\hline
\end{tabular}

Figura 5. Descrição do campo Dados Controle de um pacote PC.

- PC comum - recebe 1 se o PC possuir o formato padrão e 0 se o PC carrega pelo menos um dos campos extras;

- Dados transmissor - recebe 1 se o PC carregar os dados extras do transmissor e 0 caso contrário;

- Dados vizinhos - recebe 1 se o campo Dados vizinhos, do PC, contem dados de pelo menos um vizinho a 1 salto do Tx. Neste caso, pelo menos um dos dois próximos campos (Dados vizinhos completo e Dados vizinhos parcial) deve receber o valor 1. Caso Dados vizinhos receba 0 , os dois próximos campos, também, devem receber o valor 0 , indicando que o PC não carrega dados extras dos vizinhos do Tx. 
- Dados vizinhos completo - recebe 1 se o PC carrega toda a tabela de vizinhos a 1 salto (TB1) do Tx;

- Dados vizinhos parcial - recebe 1 se o PC carrega, apenas, os dados dos vizinhos a 1 salto do Tx que sofreram alterações;

- Tem RTS? - recebe 1 se o PC carrega uma requisição de transmissão de dados (RTS) destinada a um vizinho do nível $h-1$, em relação ao Tx.

2) Estrutura dos Campos "Dados Extras do Transmissor"e "Dados dos Vizinhos": Os dados dos campos Dados Extras do Transmissor e Dados dos Vizinhos são uteis para que cada nó construa e mantenha atualizadas as tabelas de vizinhos localizados a 1 salto (TB1) e a 2 saltos (TB2).

O campo Dados Extras do Transmissor (Fig. 6) carrega dados adicionais do transmissor do PC. Esse campo é preenchido se, e somente se, os dados do Tx sofreram alterações que exijam o reenvio. Essa estrutura se subdivide em Energia residual do Tx e o Grau do nó (parte inferior esquerda da Fig. 6). O Grau do nó $\left(G_{n}\right)$ recebe a quantidade de vizinhos do Tx, localizados no nível $h-1$. No exemplo da Fig. 1, o grau do nó Tx é três $\left(G_{T x}=3\right)$, visto que os vizinhos a 1 salto de Tx, localizados no nível $h-1$, são os nós 3,4 e 5 .

\begin{tabular}{|c|c|c|c|c|c|c|c|c|c|c|}
\hline Bytes: 1 & 4 & & 2 & 4 & Variável & Variável & \multicolumn{2}{|c|}{ Variável } & \multicolumn{2}{|c|}{ Variável } \\
\hline $\begin{array}{l}\text { Dados } \\
\text { Controle }\end{array}$ & \begin{tabular}{c|} 
ID \\
Transmissor
\end{tabular} & N. S & Saltos & \begin{tabular}{|c|} 
Tempo \\
restante
\end{tabular} & $\begin{array}{c}\text { Dados extras } \\
\text { transmissor }\end{array}$ & \begin{tabular}{|c|} 
Dados \\
vizinhos
\end{tabular} & \multicolumn{2}{|c|}{ RTS } & \multicolumn{2}{|c|}{$\begin{array}{c}\text { Agenda } \\
\text { TDMA }\end{array}$} \\
\hline & Bytes & & 4 & & ytes: 4 & 2 & & 4 & & 4 \\
\hline & Grau d & o nó & ó|Ener & gia & vizinho|N. saltc & os $\mathrm{Grau}$ & do nó & Enel & rgia & RSSI \\
\hline
\end{tabular}

Figura 6. Descrição dos campos Dados extras transmissor e Dados vizinhos de um pacote PC.

Já o campo Dados dos Vizinhos, carrega os dados dos vizinhos a 1 salto do Tx (parte inferior direita da Fig. 6). Os campos da parte branca são preenchidos para todos os vizinhos a 1 salto do Tx, pertencentes a qualquer nível. Já os campos da parte cinza são preenchidos, somente, se o nível desse vizinho for $h-1$, em relação ao Tx. A estrutura Dados Vizinhos é composta pelos seguintes os campos:

- ID do vizinho - identifica o nó vizinho a 1 salto;

- N. de saltos - distância ou nível do vizinho em relação à BS.

- Grau do nó - recebe a quantidade de nós do nível $h-2$, vizinhos do nó identificado por ID do vizinho, pertencente ao nível $h-1$. No exemplo da Fig. 1 , o nó de $I D=4$ de nível $h-1$, vizinho do Tx do PC, possui grau dois $\left(G_{4}=2\right)$, visto que possui dois vizinhos pertencentes ao nível $h-2$, os nós 6 e 7 .

- RSSI - indicador da potência do sinal do PC recebido pelo vizinho, identificado por ID do vizinho (do nível $h-1$ ) e enviado por um vizinho do nível $h-2$. Por exemplo, o RSSI do sinal de um PC enviado pelo nó 6 e recebido pelo nó 4 (Fig. 1).

- Energia - energia residual do vizinho do Tx, pertencente ao nível $h-1$.

3) Estrutura dos Campos "RTS"e "Agenda TDMA": Quando um nó precisa enviar dados para a BS ele cria uma requisição para transmitir (RTS) e a acrescenta no próximo PC a ser enviado. O campo RTS traz o identificador (ID) do nó destino da comunicação, o canal a ser reservado, o ITLC em que deverá se iniciar a transmissão e o total de ITLCs necessários. Ao enviar uma RTS no PC o nó deve enviar, também, a sua agenda TDMA.

A agenda TDMA registra todas as transmissões previstas, na vizinhança a até 2 saltos, para o período PLC do superquadro atual. O objetivo dessa agenda é sincronizar o par, transmissorreceptor, para que possam estar acordados ao mesmo tempo e sintonizados no mesmo canal. Outro objetivo é prevenir colisões de pacotes e interferências, evitando-se que duas transmissões, a até dois saltos, sejam realizadas no mesmo canal e ao mesmo tempo evitando-se, assim, o problema do terminal escondido. A estrutura dos campos RTS e Agenda TDMA estão ilustrados na parte inferior da Fig. 7.

\begin{tabular}{|c|c|c|c|c|c|c|c|c|}
\hline Bytes: 1 & 4 & 2 & 4 & Variável & Variáv & el Variável & \multicolumn{2}{|c|}{ Variável } \\
\hline $\begin{array}{c}\text { Dados } \\
\text { Controle }\end{array}$ & $\begin{array}{c}\text { ID } \\
\text { Transmisso } \\
\end{array}$ & or N. Salto & \begin{tabular}{l|l} 
tos & $\begin{array}{l}\text { Tempo } \\
\text { restante }\end{array}$ \\
\end{tabular} & $\begin{array}{c}\text { Dados extras } \\
\text { transmissor }\end{array}$ & \begin{tabular}{|c|c|} 
& Dados \\
vizinho
\end{tabular} & RTS & $\begin{array}{r}\text { Agend } \\
\text { TDMA }\end{array}$ & \\
\hline Bytes: 4 & 1 & 1 & 1 & Bytes: 4 & 4 & 1 & 1 & 1 \\
\hline $\begin{array}{l}\text { ID } \\
\text { destino }\end{array}$ & \begin{tabular}{|l|} 
Canal \\
reservado
\end{tabular} & \begin{tabular}{|l|l} 
ITLC & TC \\
de início & IT \\
\end{tabular} & $\begin{array}{l}\text { Total de } \\
\text { ITLC }\end{array}$ & \begin{tabular}{|l|l} 
ID & II \\
origem & d \\
\end{tabular} & \begin{tabular}{|l|l} 
ID & destino \\
de
\end{tabular} & \begin{tabular}{l|l} 
Canal & I \\
reservado
\end{tabular} & \begin{tabular}{|l|} 
ITLC de \\
início
\end{tabular} & $\begin{array}{l}\text { Total de } \\
\text { ITLC }\end{array}$ \\
\hline
\end{tabular}

Figura 7. PC com requisição para transmitir dados (RTS) e agenda TDMA.

Os nós que agendaram uma transmissão, acordam no ITLC de início e mudam para o canal combinado. Caso um ITLC, do período PLC, não seja suficiente para a transmissão dos dados, mais de um intervalo de tempo pode ser reservado (Fig. 8). Caso necessário, essa transmissão pode se estender por todo o período inativo enquanto os demais nós permanecem dormindo até o próximo superquadro.

A Fig. 8 ilustra os pares transmissores-receptores $(1 \rightarrow 2$, $4 \rightarrow 3 \ldots$ ), durante o PCA, combinando o canal e os ITLCs que serão utilizados para a troca de dados no PLC. Nesse exemplo, existem 8 nós vizinhos, localizados a até 2 saltos uns dos outros. As três linhas, na horizontal, representam os canais 11,13 e 15 . O período ativo é dividido em 16 intervalos de tempo de igual tamanho, numerados de 0 a 15. Cada um dos 8 nós bisbilhotam os pacotes RTS e CTS enviados pelos demais, durante o PCA, de forma que ao final desse período cada um desses nós terão em suas agendas o conhecimento de todas as transmissões que ocorrerão no período PLC ou, até mesmo, no PI como ocorre na transmissão do nó 7 para o nó 2 no canal 15 (Fig. 8).

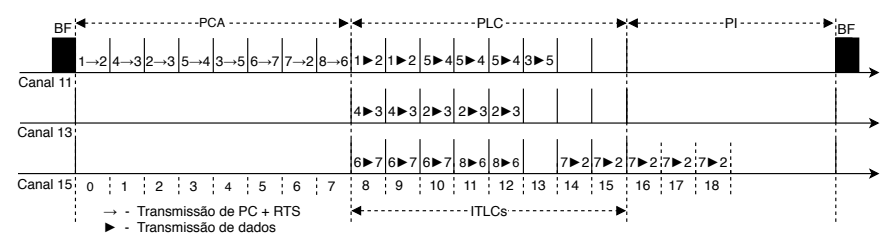

Figura 8. Exemplo de agendamento de canal e ITLCs para o PLC. 


\section{B. Estrutura do Pacote CTS}

Quando um nó receptor identifica que ele é o destinatário de uma RTS, então, ele verifica na sua agenda TDMA se o canal e os ITLCs requisitados estão disponíveis para a transmissão. Se estiverem disponíveis, esse nó gera uma mensagem CTS (Fig. 9), direcionada ao emissor da RTS, confirmando a participação na troca de dados. Se não estiverem disponíveis, mesmo assim é enviado um CTS, mas com a informação de que a RTS foi rejeitado e por quais motivos.

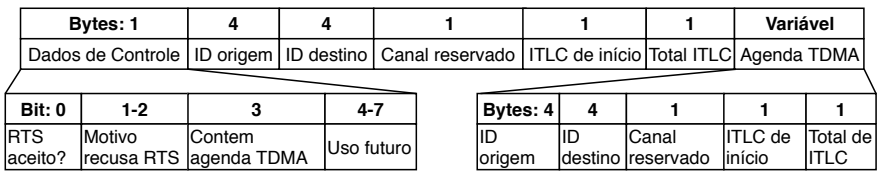

Figura 9. Mensagem de confirmação de participação em troca de dados (CTS) durante o PLC.

A mensagem CTS, assim como a RTS, carrega informações sobre o canal e os ITLCs que serão utilizados na transmissão. O CTS carrega, também, a agenda TDMA das transmissões do PLC a serem realizadas pelos vizinhos a 1 e a 2 saltos. A agenda TDMA é enviada tanto no PC, que contém o RTS, quanto em pacotes CTS, a fim de evitar o problema do terminal escondido [18].

Quando o nó emissor da RTS recebe o CTS, então, ele verifica se o destinatário aceitou a transmissão no canal e ITLCs propostos. Começado o período PLC, emissor e receptor desligam seus rádios até o ITLC combinado para o início do envio e recepção de dados.

Caso a RTS não tenha sido aceito, esse nó aguarda o início do próximo IT, no mesmo superquadro ou no próximo para, novamente, disputar e tentar enviar outro PC com RTS. Esse novo PC contém outro canal ou outros ITLCs que não estejam sendo usados na vizinhança.

\section{Visão Geral do Período de Contenção para Acesso ao Meio (PCA)}

Durante o período PCA, todos os nós permanecem acordados e sintonizados no canal de controle. A Fig. 10 ilustra as principais atividades realizadas durante o PCA. A RSSF representada é composta por uma BS e três nós sensores. As linhas tracejadas, na vertical, delimitam dois intervalos de tempo do PCA. As atividades realizadas são numeradas de 1 a 10, na parte inferior da figura. As setas para cima e para baixo representam pacotes PCs enviados pela BS e pelos nós sensores. Os retângulos na cor cinza ilustram o momento e o dispositivo que está transmitindo um PC ou um CTS. Já os retângulos na cor branca podem representar: a recepção $(\mathrm{Rx})$ de um PC; um período para contenção para ter acesso ao meio $(\mathrm{CW})$; ou apenas um período de escuta em baixa potência, no qual o nó aguarda o encerramento da atividade da qual ele não participa.

No início (atividade 1 no eixo do tempo), a BS envia um pacote $\mathrm{BF}$ empregando potência de transmissão suficiente para alcançar todos os nós da rede. Em seguida, na atividade 2, a BS

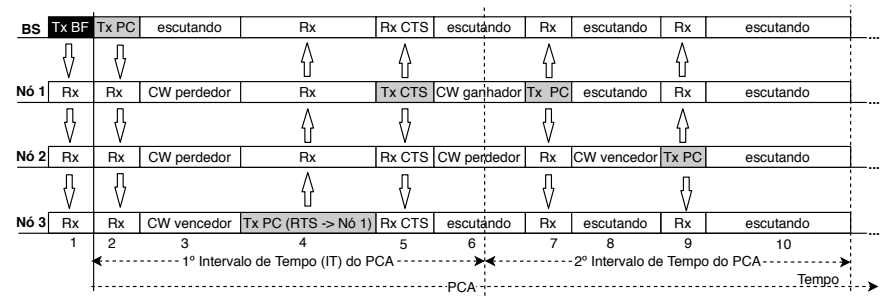

Figura 10. Atividades realizadas dentro dos intervalos de tempo do PCA.

reduz a potência de transmissão para a mesma utilizada pelos demais nós e envia o primeiro PC do PCA. Tanto o pacote $\mathrm{BF}$ quanto o $\mathrm{PC}$ são enviados pela $\mathrm{BS}$ sem que esta tenha de disputar o acesso ao meio, como na abordagem CSMA.

Após receberem o PC, enviado pela BS, cada um dos 3 nós passam a disputar o acesso ao canal para enviar o seu próprio PC (atividade 3), seguindo a abordagem CSMA/CA do 802.15.4 [5]. No exemplo da Fig. 10, o nó 3 vence a disputa e ganha o direito de enviar seu PC.

$\mathrm{Na}$ atividade 4, o nó 3 preenche o seu PC com suas próprias informações e de seus vizinhos a 1 salto. Este, também, atualiza o campo Número saltos para $h=1$ e acrescenta a esse PC uma requisição para transmissão (RTS), destinada ao nó 1, além de sua agenda TDMA. Quando os demais nós recebem o PC do nó 3 , primeiro atualizam suas agendas TDMA. Já o nó 1 identifica que ele é o destinatário da RTS contido no PC. Nesse instante, todos os nós que receberam o PC do nó 3 sabem que precisam aguardar um tempo adicional para que o destinatário da RTS possa responder com um CTS.

$\mathrm{Na}$ atividade 5, o nó 1 envia um CTS destinado ao nó 3 confirmando ou rejeitando a participação na transmissão requerida na RTS. Os demais nós, ao receberem esse CTS atualizam suas agendas TDMA. Na atividade 6 , apenas os nós 1 e 2 disputam o canal para enviarem seu PC, enquanto que, o nó 3 , simplesmente, faz uma escuta, pois sabe que esse período está reservado para contenção para acesso ao meio. Nesse caso o nó 1 é o vencedor. Vale destacar que a atividade 6 começa no primeiro IT e termina no segundo.

Na atividade 7, o nó 1 constrói e envia seu PC com suas informações e de seus vizinhos a 1 salto. Como esse PC não carrega RTS, não há necessidade de que os demais nós esperem um tempo adicional reservado para recepção de CTS. $\mathrm{Na}$ atividade 8, apenas o nó 2 tenta acessar o meio, pois os nós 1 e 3 já enviaram seu PC no superquadro atual.

Já na atividade 9, o nó 2 envia seu PC sem uma RTS. Por fim, na décima atividade, visto que todos os nós já enviaram seus PCs no superquadro, todos entram em um estado de escuta até o fim do PCA.

\section{Tabelas de Vizinhos a 1 e a 2 Saltos}

Toda vez que um dado nó da RSSF recebe um pacote PC, este constrói ou atualiza suas tabelas de vizinhos a 1 salto (TB1, ver Fig. 11) e a 2 saltos (TB2, ver Fig. 12). A esse nó nomearemos construtor das tabelas (CT). Essas tabelas são fundamentais para o conhecimento da estrutura da rede, 
para o roteamento e para a escolha de canais de comunicação disponíveis.

\section{\begin{tabular}{|l|l|l|l|l|l|l|}
\hline N. Sequência & RSPC & Houve alteração & ID vizinho 2 salto & N. Saltos & Grau & Energia \\
\hline
\end{tabular}}

Figura 11. Estrutura da tabela de vizinhos a 1 salto (TB1).

Além dos atributos já conhecidos e descritos, nas seções anteriores, essas tabelas possuem os campos RSPC e Houve Alteração. O RSPC registra se os dados da tupla, referente a um vizinho, foram recebidos no $\mathrm{PC}$ atual ou se são os mesmos enviados em superquadros anteriores. Já o campo Houve Alteração registra se houve alterações nos dados de um nó vizinho ou não.

$\mathrm{Na}$ tabela de vizinhos a 2 saltos (Fig. 12) os cinco primeiros campos dessa tabela são preenchidos para todos os vizinhos a 2 saltos do nó CT. Já os campos Grau, Energia e RSSI registram, apenas, os dados dos vizinhos a 2 saltos do nível $h-2$.

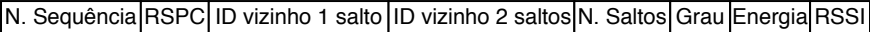

Figura 12. Estrutura da tabela de vizinhos a 2 saltos (TB2).

\section{Técnica PARA ReduÇÃo de Sobrecarga de PACOTES DE CONTROLE}

A técnica de redução de sobrecarga de pacotes de controle (RSPC) visa reduzir a quantidade de dados de controle circulando pela rede. Com isso, espera-se prolongar o tempo de vida da rede sem, no entanto, reduzir a quantidade e a qualidade dos dados disponíveis na vizinhança.

Os Algoritmos 1 e 2 representam, respectivamente, os procedimentos do RSPC que são executados no transmissor e no receptor de pacotes PC. A execução desses algoritmos causam um visível aumento na quantidade de processamento e, portanto, maior gasto de energia com o processamento. Todavia, esse aumento é compensado pela redução no consumo de energia proporcionado pela técnica de redução do overhead, pois o custo energético para transmissão de dados é muito maior que o custo de processamento de instruções [4].

No Algoritmo 1 são descritas as atividades executadas em cada nó antes dele enviar seu PC. O transmissor (Tx) do PC executa essas ações para avaliar se os dados enviados por ele (Tx) e disponíveis nas tabelas de seus vizinhos a 1 salto ainda são válidos ou se é necessário o envio de dados mais atuais.

Os dados de entrada, no Algoritmo 1, recebe dados dos vizinhos a 1 salto contidos na TB1 do nó Tx. O grau de conectividade, a energia residual, o RSSI e o número de saltos são os principais dados necessários para execução desse algoritmo.

No primeiro e no segundo teste condicional do Algoritmo 1, para cada um dos vizinhos a 1 salto do nó Tx, é verificado se ocorreram alterações no grau de conectividade, no nível de energia ou se houve variação da energia residual ou do RSSI além de um determinado limite. Se algumas dessas condições forem verdadeiras essas mudanças devem ser enviadas no PC.
Caso nenhuma alteração tenha sido registrada ou, caso estas estejam dentro dos limites permitidos o PC não recebe dados extras dos vizinhos a 1 salto.

Já no terceiro teste condicional do Algoritmo 1 é verificado se ocorreram alterações no próprio transmissor do PC. Caso tenham ocorrido alterações no grau de conectividade, variações na energia residual ou no RSSI, além dos limites permitidos, essas informações devem ser acrescentadas no PC no campo Dados dos Vizinhos. Caso nenhuma alteração tenha sido verificada o PC não recebe dados extras do transmissor.

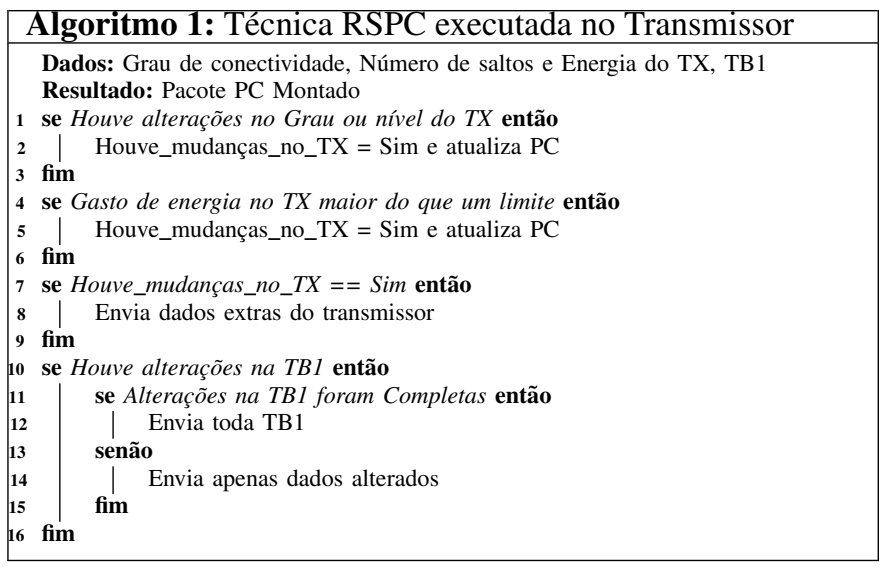

No Algoritmo 2 são descritas as atividades executadas em cada receptor $(\mathrm{Rx})$ de PCs. O Rx executa essas ações para avaliar se será necessário atualizar suas tabelas (TB1 e TB2) com as novas informações do Tx e seus vizinhos.

Os dados de entrada no Algoritmo 2 são: o RSSI medido ao receber o $\mathrm{PC}$, os dados contidos no $\mathrm{PC}$ e os dados dos vizinhos já disponíveis nas tabelas TB1 e TB2. Como resultado desse processamento as tabelas TB1 e TB2 são atualizadas com o estado atual da vizinhança.

$\mathrm{O}$ primeiro teste condicional é verificado se o nível (distância), do vizinho $\mathrm{Tx}$ do $\mathrm{PC}$, for maior ou igual ao nível do Rx. Se verdadeiro, significa que o Tx não é um possível retransmissor de dados do Rx. Por isso, não será medido o RSSI do PC recebido e não serão lidos os dados do campo Dados Extras do Transmissor. Já os dados do campo Dados dos Vizinhos serão lidos, todavia, apenas os atributos ID vizinho e $N$. saltos, já os demais atributos (parte cinza da Fig. 6) só são preenchidos para potenciais retransmissores de dados.

Se, todavia, o resultado do primeiro teste condicional (Algoritmo 2) for falso, significa que o Tx é um potencial retransmissor de dados do $\mathrm{Rx}$ do $\mathrm{PC}$, por estar um salto mais próximo da BS do que o Rx do PC. Para este caso, é avaliado se ocorreram alterações no RSSI e nos dados do Tx, bem como nos dados do campo Dados Extras do Transmissor do nó Tx do PC.

É verificado, também, se ocorreram alterações nos dados dos vizinhos do Tx e se estas foram completas ou parciais, de forma que, os dados da TB2 são atualizados conforme a situação. Para os vizinhos do Tx, localizados no nível $h-2$, 
são preenchidos todos os atributos do campo Dados Vizinhos (Fig. 6). Já para os demais nós apenas os atributos básicos (ID vizinho e N. saltos) são preenchidos (Fig. 6).

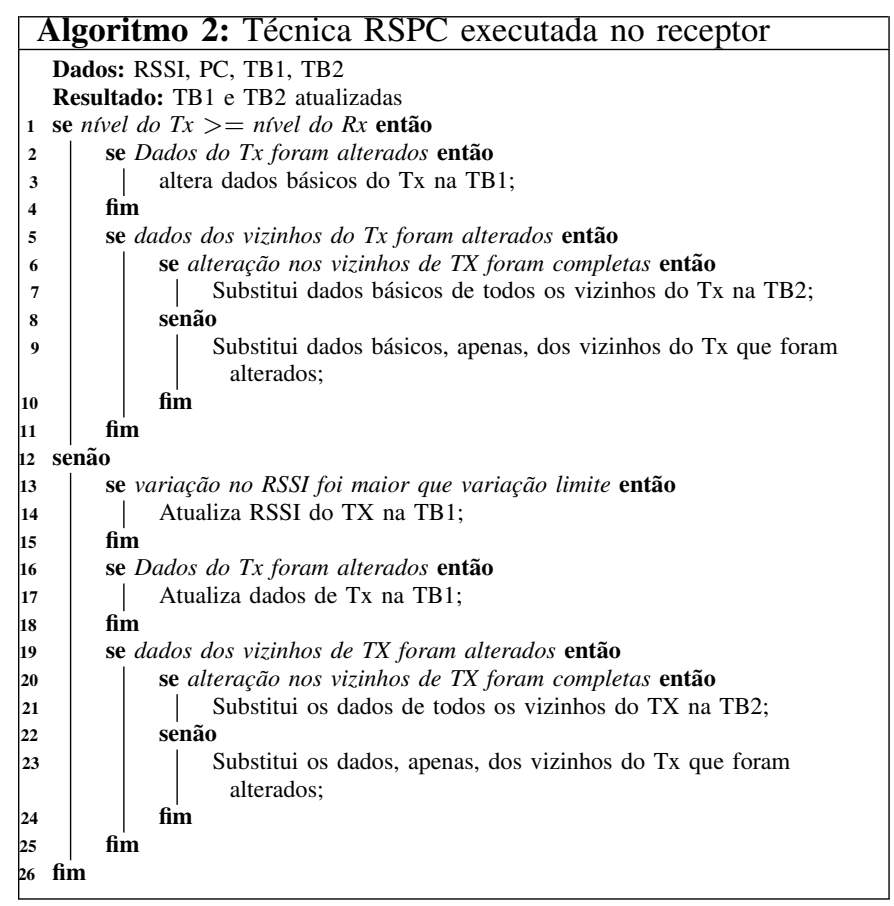

\section{Demonstração do POTENCIAL DE REDUÇÃo DE SOBRECARGA DA TÉCNICA RSPC}

Dada a rede da Fig. 13, composta por seis nós e uma BS, seja o nó TX o transmissor de mensagens PC. Os pacotes PCs, enviados por difusão, são representados pelas setas ao lado das arestas, os quais são destinados aos vizinhos a 1 salto, aqui denominados receptores (RXs).

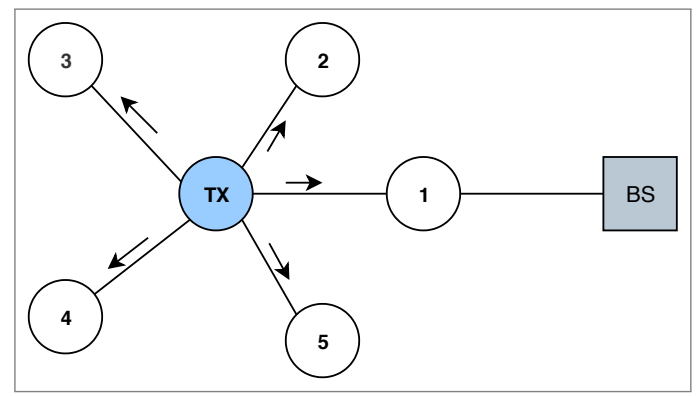

Figura 13. RSSF com 1 nó transmissor (TX) de PCs e 5 receptores (RX).

Neste exemplo, TX envia dois tipos de pacotes: O PC completo, que traz pelo menos um dos campos, Dados Extras do Transmissor e Dados Vizinhos, preenchidos; e o PC padrão, o qual não carrega dados extras do próprio TX e nem dos seus vizinhos.

Uma simulação do funcionamento aqui é proposta a fim de demonstrar que a técnica RSPC pode reduzir a quantidade de bytes de controle na rede. Assim, é avaliada a quantidade de bytes de controle gerados em um período de envio de pacotes
PCs. O objetivo deste exemplo é comparar o total de bytes enviados pelo nó TX, no cenário em que é usado RSPC com o outro onde a técnica não é utilizada. A Tabela I traz os parâmetros utilizados na simulação.

Tabela I

PARÂMETROS DA SIMULAÇÃo UTILIZANDO, OU NÃO, A TÉCNICA RSPC.

\begin{tabular}{|l|c|l|}
\hline Variáveis & Valor & Descrição \\
\hline Bpad & 11 & Total de bytes do PC padrão \\
\hline Btx & 6 & Bytes do campo Dados extras transmissor \\
\hline B1hop & 16 & Total de bytes de cada vizinho a 1 salto \\
\hline Nviz & 5 & Número de vizinhos do nó transmissor \\
\hline Bpc & 97 & Total de bytes de um PC completo (Eq. 1) \\
\hline Periodo & $2,3,5,15,30$ & Quantidade de PCs enviados por período \\
\hline
\end{tabular}

A quantidade de PCs enviados a cada Período, para o exemplo em questão, recebe os valores fixos $2,3,5,15,30$. Na Fig. 13, o nó $T X$ possui 5 vizinhos, de forma que um PC completo, enviado por $T X$, possui 97 bytes calculado de acordo com

$$
B p c=B p a d+B t x+(B 1 h o p \times N v i z) .
$$

Já o PC padrão, sem nenhum dado extra, contém 11 bytes (Bpad). Por outro lado, a equação

$$
\text { Bsrspc }=\text { Bpc } \times \text { Periodo. }
$$

calcula o total de bytes, dos PCs completos, enviados por $T X$ em um período sem o uso de RSPC ( $B s r s p c)$. Nessa equação, $B s r s p c$ recebe o total de bytes de um PC completo $(B p c)$ vezes o período (Periodo). Já a equação (3)

$$
B r s p c=B p c+(\text { Periodo }-1) \times \text { Bpad }
$$

modela o total de bytes enviados pelo $T X$ em um período usando a técnica do RSPC ( $B r s p c)$. Neste exemplo, em cada período, primeiro é enviado um PC completo para que os vizinhos de $T X$ tomem conhecimento sobre os vizinhos desse nó. Os demais pacotes de controle devem ser PCs padrão até o fim do período. Uma série temporal com 2 períodos usando RSPC, em que Periodo $=5$, pode ser ilustrada como: (97, $11,11,11,11,97,11,11,11,11 \ldots)$.

No cálculo da Eq. (3), o termo (Periodo -1$) \times$ Bpad traz o total de bytes de PCs padrão enviados por período. E depois esse valor é somado a $B p c$ resultando no total de bytes enviados em um período usando RSPC.

Os resultados dessa simulação são apresentados na Fig. 14 que ilustra o total de bytes de controle enviados (eixo y) e no eixo $x$ são destacados cada período. Esse gráfico mostra a quantidade de bytes de controle enviados, em apenas 1 período, usando a técnica RSPC (barras vermelhas) e sem o uso da técnica RSPC (barras azuis).

$\mathrm{Na}$ Fig. 14, quando Periodo assume os valores $2,3,5,10,15,30$, ao se usar a técnica RSPC (barras vermelhas), é obtida, respectivamente, uma redução de 79,63\%, $144,54 \%, 243,97 \%, 479,68 \%$ e $599,52 \%$ em relação ao envio de PC sem o RSPC. Nota-se, no gráfico, que a diferença na 


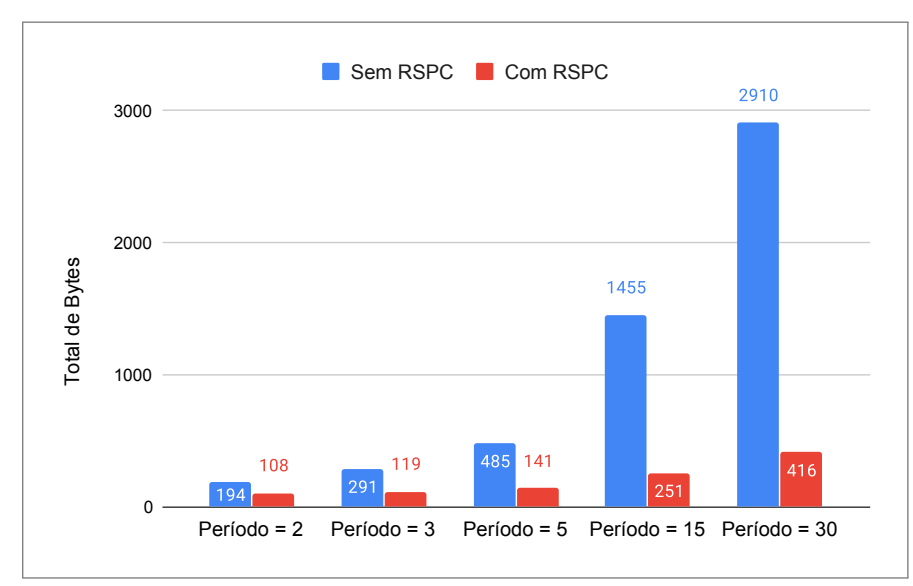

Figura 14. Total de bytes de controle enviados pelo nó transmissor.

redução da quantidade de bytes de controle cresce linearmente de maneira expressiva.

Embora essa simulação não reflita, integralmente, o que aconteceria em um ambiente com execução real do protocolo proposto, ela demonstra que a abordagem tem potencial para reduzir a quantidade de dados de controle na rede e, consequentemente, o consumo de energia.

É importante destacar que, no protocolo proposto, a redução na quantidade de bytes pode ser ainda maior. Isso porque, neste o $T X$ somente envia um PC completo quando todos os seus vizinhos sofrerem alterações que justifiquem o envio de todos os dados atuais.

\section{CONCLUSÕES}

Este trabalho propõe o MAC-RSPC, o qual é uma proposta de protocolo MAC para redução de sobrecarga de pacotes de controle em redes de sensores sem fio (RSSFs) multicanais e homogêneas. O objetivo da técnica RSPC é reduzir o overhead de dados de controle que são enviados na rede e com isso aumentar o tempo de vida da rede, haja vista que, o envio e recepção de dados são as atividades que mais demandam energia em RSSFs.

O MAC-RSPC segue a abordagem cross-layer que visa disponibilizar às camadas superiores dados sobre a reserva energética e a qualidade do canal dos vizinhos. Isso para que, decisões sobre roteamento e balanceamento de carga e consumo energético possam ser tomadas por protocolos dessas camadas.

A ideia do MAC-RSPC é que cada nó, em um primeiro momento, informe a todos os seus vizinhos o estado do enlace de cada um dos seus vizinhos a até 2 saltos. Depois essas informações só são enviadas se ocorrerem alterações na vizinhança desse nó que ultrapassem os limites definidos pelo RSPC.

Foi realizada, também, a demonstração do potencial de redução de sobrecarga de dados de controle da RSPC. Essa técnica se mostrou promissora, de forma que cada nó pode dispor de uma grande quantidade de dados sobre seus vizinhos a até 2 saltos, com baixo overhead.
Como proposta de trabalhos futuros, pretende-se implementar o MAC-RSPC em um simulador de redes e compará-lo com outros protocolos MAC. Pretende-se, ainda, implementar um protocolo de roteamento que faça uso dos dados da energia residual, do RSSI e do grau de conectividade para construção de rotas tolerantes a falhas e energeticamente eficientes.

\section{REFERÊNCIAS}

[1] L. K. Ketshabetswe, A. M. Zungeru, M. Mangwala, J. M. Chuma and B. Sigweni, "Communication protocols for wireless sensor networks: A survey and comparison," Heliyon, vol. 5, pp. 1-43, May 2019.

[2] W. Rehan, S. Fischer, M. Rehan and M. H. Rehmani, "A comprehensive survey on multichannel routing in wireless sensor networks," Journal of Network and Computer Applications, vol. 95, pp. 1-25, Octuber 2017.

[3] C. Dong and F. Yu, "A prediction-based asynchronous MAC protocol for heavy traffic load in wireless sensor networks," International Journal of Electronics and Communications, vol. 82, pp. 241-250, December 2017.

[4] A. I. Al-Sulaifanie, S. Biswas and K. Al-Sulaifanie, "AH-MAC: adaptive hierarchical MAC protocol for low-rate wireless sensor network applications," Journal of Sensors, vol. 2017, pp. 1-15, January 2017.

[5] IEEE Standards Association and others, "IEEE standard for local and metropolitan area networks-part 15.4: low-rate wireless personal area networks (LR-WPANs)- IEEE Std 802.15.4-2011 (Revision of IEEE Std 802.15.4-2006)," IEEE Computer Society, New York- NY, 2011.

[6] Y. Liu, A. Liu, N. Zhang, X. Liu, M. Mad and Y. Hu, "DDC: Dynamic duty cycle for improving delay and energy efficiency in wireless sensor networks," Journal of Network and Comoputer Applications, vol. 131, pp. 16-27, April 2019.

[7] A. Boukerche and X. Zhou, "A Novel Hybrid MAC Protocol for Sustainable Delay-Tolerant Wireless Sensor Networks," IEEE Transactions on Sustainable Computing, February 2020.

[8] P. M. Prathibhavani and T. G. Basavaraju, "Energy-Efficient MACROUTE Cross-layer Optimal Distance Chain Protocol for Wireless Sensor Network," In Optical and Wireless Technologies, Springer, Singapore, April 2020.

[9] B. Fu, Y. Xiao, H. Deng and H. Zeng, "A survey of cross-layer designs in wireless networks," IEEE Communications Surveys and Tutorials, $\mathrm{n}$. 1, vol. 16, pp. 110-126, Fisrt Quarter 2014.

[10] G. Li, E. Geng, Z. Ye, Y. Xu, J. Lin and Y. Pang, "Indoor Positioning Algorithm Based on the Improved RSSI Distance Model," Sensors, vol. 18, pp. 2820, August 2018.

[11] L. Cheng, J. Hang, Y. Wang and Y. Bi, "A Fuzzy C-Means and Hierarchical Voting Based RSSI Quantify Localization Method for Wireless Sensor Network," IEEE Access, vol. 7, pp. 47411-47422, April 2019.

[12] L. Wang, J. Yan, T. Han and D. Deng, "On Connectivity and Energy Efficiency for Sleeping-Schedule-Based Wireless Sensor Networks,"Sensors (Basel), vol. 19, May 2019.

[13] A. Boukerche and X. Zhou, "A Novel Hybrid MAC Protocol for Sustainable Delay-Tolerant Wireless Sensor Network," in IEEE Transactions on Sustainable Computing, pp. 1-1 February 2020.

[14] Y. Zhang and L. Jiang, "A New Wireless Sensor Network MAC Protocol: NSMAC," Journal of Physics: Conference Series, Vol. 1345, pp. 042018, November 2019.

[15] S. Siddiqui, S. Ghani, A. Anwar and A. Khan, "ADP-MAC: An Adaptive and Dynamic Polling based MAC Protocol for Wireless Sensor Networks," IEEE Sensors Journal, n. 2, vol. 18, pp. 860-874, January 2018.

[16] G. Sakya and V. Sharma, "ADMC-MAC: Energy efficient adaptive MAC protocol for mission critical applications in WSN," Sustainable Computing: Informatics and Systems, vol. May 2019.

[17] Y. Kim, H. Shin and H. Cha, "Y-mac: An energy-efficient multi-channel mac protocol for dense wireless sensor networks," in Proceedings of the 7th international conference on Information processing in sensor networks, St. Louis, MO, April 2008.

[18] O. D. Incel, "A survey on multi-channel communication in wireless sensor networks," Computer Networks, n. 13, vol. 13, pp. 3081-3099, September 2011. 